\title{
Assess Obese Patient Readiness to Decrease Weight: A Practical Approach
}

\author{
Al-Saleh MM and Algarni AM* \\ Department of Family Medicine, Health Affairs, Aseer \\ Region, Kingdom of Saudi Arabia \\ *Corresponding author: Abdullah Mohammed \\ Algarni, Department of Family Medicine, Health Affairs, \\ Aseer Region, Kingdom of Saudi Arabia
}

Received: J une 30, 2017; Accepted: J uly 25, 2017;

Published: August 01, 2017

\begin{abstract}
Obesity is common, major health problem. The trend of obesity incidence and prevalence in Saudi Arabia are not reassuring. Thoughts and behavior are major risk factors for obesity specifically and unhealthy lifestyle overall. Changing thoughts and behaviors are feasible function of primary care physician although not easy at all time.
\end{abstract}

Keywords: Assess; Obese patient; Obesity

\section{Introduction}

Obesity became a major health problem [1,2]. It is estimated that worldwide prevalence of overweight or obesity is $36.9 \%$ in men and 38\% in women in 2013 [2]. In the last Saudi health information survey for non-communicable diseases in Saudi Arabia (SHIS-2013), the prevalence of overweight and obesity (defined by body mass index (BMI) was $30.7 \%$ and $28.7 \%$ respectively [3]. The prevalence of overweight and obesity among Saudi male was $33.4 \%$ and $24.1 \%$ respectively, and among Saudi female was $28 \%$ and $33.5 \%$ respectively [3]. In the last update of the Global Burden of Disease (GBD) study, Saudi Arabia was among highest countries in mean of increment in the prevalence of obesity [2]. High body mass index (BMI) accounted for the highest attributable disability-adjusted life-years (DALYs) in Saudi Arabia [4]. Unfortunately, the trend of obesity in Saudi Arabia is not reassuring [5].

The complications of obesity are well known. All causes of mortality are increased [6,7] as well as specific-causes of mortality, especially those suffering from morbid obesity (BMI $\geq 40 \mathrm{~kg} / \mathrm{m}^{2}$ ) [6-13]. Greater waist circumference associated also with increased all-cause mortality in men and women [14]. However, not only the mortality increased, also there is increased in morbidity $[15,16]$. Heart diseases [17-21], stroke [22,23], hypertension [24,25], diabetes mellitus [26-29], dyslipidemia [30,31], venous thromboembolism (VTE) [32,33], cancer [34-37], dementia [38], maternal and fetal complications [39-42], osteoarthritis [43-45], and gastroesophageal reflux disease (GERD) [46] are increased with more gain in weight.

Obesity is frequently seen in clinical practice by family physicians. Management of obesity is challenging for patient as well as physician. It is important to recognize two things regarding obesity. First, that obesity is not an isolated biological disturbance. Instead, it has a multiple aspect (psychological, social and biological). Second, it is a direct reflection of patients eating habits and his/her life style patterns. By putting the above notes in mind, obese patient need help of his physician in changing unhealthy behaviors as one role of family physician is assisting the patient to do such mission [47]. Behavioral changes usually going slowly with recurrent relapses, so the patient needs continuous assessment and support through this process. Understanding the readiness of patient to change and monitor his advancement is crucial for successful change of behavior [47-49].
Transtheoretical Model of Change, also known as the Stages of Change model by Prochaska and Diclemente [50] first used to help alcoholics to quit. It measures the readiness of patient to change his behavior as well as provides a frame of the change process. It is validated and effective in weight reduction as well as other problematic behaviors [51-56]. Table 1 summarizes the Stages of Change model and physician goal at each stage [49]. In the following section, we are going to display a practical approach for the Stages of Change model for an obese patient.

\section{Case Scenario}

Saad is a 35 years old Saudi male came to youfor promotion clinic and annual check-up.You note that he is obese, how family physician can measure readiness of Saad to decrease his weight and help him to change his behavior?

\section{Initial visit}

Family physician should start consultation with welcoming Saad, thanks him for attendance to clinic, establishing with him a good rapport in order to conduct a successful consultation.

Family physician starts by collecting biodata and then asking an open-ended question, such as "how is your health status?" Saad ideas, concerns should be adequately explored; the real reason and expectation from this visit are important issues that should be addressed in initial visit. Family physician decided to discuss with Saad his weight in the current visit.

\section{Presenting illness history and systemic review}

Present complaint and past medical history, dietary and physical activity should be covered completely. The following important points are mandatory [57]:

- Duration of obesity.

- Onset of obesity, aggravation as well as reliving factors.

- Effects of obesity on Saad's on health and his quality of life as all.

- Detailed dietary history should include; number of meals, snacks, intake fast food, intake soft drinks, taking breakfast regularly, intake of fruits and vegetables.

- Other important issue is physical activity and sedentary
J Fam Med - Volume 4 Issue 4 - 2017

ISSN : 2380-0658 | www.austinpublishing group.com

Algarni et al. (C) All rights are reserved
Citation: Al-Saleh MM and Algarni AM. Assess Obese Patient Readiness to Decrease Weight: A Practical Approach. J Fam Med. 2017; 4(4): 1121. 
Table 1: The stages of change model and physician goal at each stage.



life. Family physician should explore the patterns of daily physical activity, practicing sport at schools (type, frequency, duration) and watching TV or play stations if any.

- Family history of chronic diseases such as obesity, diabetes, hypertension, dyslipidemia and cardiovascular diseases is another aspect that should be covered.

- Social history to check level of education, financial status, nature of Saad's job, smoking, alcohol, and substance abuse.

- Psychiatric history to cover mood change, psychotic disorders, personality disorder, and eating disorders.

Details history from Saad showed that he is a 35 years old working mathematics teacher in elementary school. Heis in good health generally but showed to gain weight for the last 5 years, dietary history revealed that Saad intakes soft drink like sweet juices and cola. Most of days Saad has breakfast in the school with his friends. After back to home from school, Saad has his launch which consists of Kabsa, soft drink and sometimes Laban. There were less then $1-2$ serves per week of fruits and vegetables. Saad sleeps for $3 \mathrm{~h}$ and gets up at 4:00 PM to finish and to deal with his family requirements for about 2 - 3hrs. After that, Saad used to watch TV for about $3 \mathrm{~h}$ without performing any physical activity. Weekly, he used to meet his friend at night and have a dinner all together at least twice a week. The dinner differs but usually consists of Kabsa or roast goat. While watching TV, Saad eats some dates and sweets with Arabic coffee. There was no history of fatigue, hair loss, diarrhea or constipation. Saad's mood was normal and no relevant stressor. Saad addressed his concern about night snoring only. Family history revealed that Saad's father and mother are diabetic, hypertensive, and obese onmedications. There is no history of smoking in family and nor conflict with good income for family needs. Saad's performance at work is good although he sometime suffered from somnolence and recurrent yawing. However, he mentioned he still can cope with this drowsiness.

\section{Physical examination}

After taking history, then family physician should proceed to perform a comprehensive physical examination after taking the permission of Saad's and explaining to him what he is going to do. The physical examination should cover the following aspects:

- $\quad$ General look and body built

- Vital signs (including weight, height, and BMI)
- Thyroid and neck examination

- Heart and chest

- Abdomen including waist/hip ratio

- $\quad$ Back and joints

- $\quad$ Skin

Physical examination of Saad revealed the following:

Saad was looking obese, with a normal gait; nojaundiced or pallor, there was no skin pigmentation, lesions or scars. There was no acanthosis nigricans noted. Vital sign showed: $\mathrm{BP}=130 / 85 \mathrm{mmHg}$, temperature $36.7^{\circ} \mathrm{C}$, weight $=101 \mathrm{~kg}$, height $=180 \mathrm{~cm}$. BMI calculated and was $30.17 \mathrm{~kg} / \mathrm{m}^{2}$. Head, neck, ENT, thyroid was normal, heart and chest examination showed no abnormality or significant finding. Abdomen showed centrally obese but no organomegaly. There were no lower limbs swelling or deformity.

Family physician appreciated Saad cooperation during history taking and physical examination. Family physician explained the findings to Saad stating that his weight was above normal and there is no obvious cause for weight gain except intake unhealthy diet and physical inactivity. Family physician told Saad that snoring as well as somnolence and recurrent yawing is most likely due to obesity, and those with obesity are at high risk of diabetes, hypertension and dyslipidemia. Family physician informed Saad that relevant investigations are necessary to rule out secondary causes of obesity and to screen for some health problems such as hypothyroidism, diabetes, and dyslipidemia. Saad responded to his family physician diagnosis by statement that he did not believe that being overweight is a problem or carrying any risk on his health status (Precontemplation). He also wondered if that overweight causing snoring and somnolence at daytime! Family physician aimed to maintain the rapport with patient and tried to deliver the important information about obesity by indirect way to avoid shocking patient. Family physician explained to Saad that obesity is systemic disease affecting approximately every system in body and it is not isolated increase in weight. He provided Saad with educational materials as well as some social media accounts that care with obesity. Family physicians thanked Saad and give him an appointment after 1-month to complete discussion and check the results of investigations.

\section{Investations}

At this visit the following investigations were requested [49]: 
- $\quad$ Fasting Blood Glucose (FBG)

- Lipid profile (Total cholesterol [TC], high density lipoprotein $[\mathrm{HDL}]$, low density lipoprotein $[\mathrm{LDL}]$, and triglycerides [TG])

- $\quad$ Thyroid functions test (TSH, $\mathrm{T}_{3}$, and $\mathrm{T}_{4}$ )

- Liver functions test (aspartate aminotransferase [AST], alanine aminotransferase [ALT], and gamma glutamyl transferase [GGT])

$2^{\text {nd }}$ visit: Saad came on time for follow-up. Family physician greatened Saad and thanked him for attain the clinic. Brief history was taken, weight and height were checked as well as body mass index (BMI) were calculated. Investigations done and the results were normal.Saad mentioned that he read the educational materials provided from your side beside the social media caring obesity. $\mathrm{He}$ wondered about the mentioned risk in the materials about obesity. Are they supported by evidences?

(Contemplation). The family physician grabbed the opportunity and started to mention the evidences that support the detrimental effects of being obese as well as benefits of healthful weight in simple and understandable way. Also he listed obese patients' experiences before and after weight reduction in meaning of improving quality of life and ameliorating sleep adverse effects.

Again, family physician gave Saad educational materials rich in studies that demonstrated harmful effects of obesity as well as benefits of regular healthful lifestyle as well as book edited by previously obese person narrated his experience before and after weight reduction. Family physician gave Saad 1-month appointment and thanked him for attaining the clinic.

$3^{\text {rd }}$ visit: Saad came on time for the clinic. Family physician goals for this clinic were:

- Measure the changes of misconception regarding obesity

- Motivate the change in Saad's behavior

Saad stated that he reviewed the all the materials he given. $\mathrm{He}$ now believes that obesity really has multiple harmful effects on health. Hopefully, Saad started to avoid some unhealthful diets (Preparation) such as sweetened soft drinks, fast foods, and saturated fats. Family physician showed genuine interest in those preliminary steps as well as changes occurred in the believes of Saad. He promoted Saad to continue in his changing steps and joining support groups specialized in obesity. He provided Saad by illustration chart of healthy eating pyramid. Family physician thanks Saad and closed the consultation after giving him 1-month appointment.

$4^{\text {th }}$ visit: Saad came to his family physician seeking eagerly a management plan to reduce his weight. He asked if there is any prepared plan can be used to decrease his weight (Action). Family physician discussed with Saad the following approaches, pros and cons, and evidences supporting each of them [49]:

- $\quad$ Life style modification.

- Pharmacotherapy.

- $\quad$ Bariatric surgeries.
They agreed then to start by life style modification as initial intervention. They set a target of weight loss of $2 \mathrm{~kg} / \mathrm{month}$, that is, $0.5 \mathrm{~kg} /$ week and the final goal is to lose $26 \mathrm{~kg}$ which will bring his BMI to $23.1 \mathrm{~kg} / \mathrm{m}^{2}$, so duration of 13 months is seated as the amount of time needed to achieve the shared goal. Family physician and Saad agreed also discuss the following practical advices [57]:

- $\quad$ Eat five or more servings of fruits and vegetables daily

- Use television and computer for no more than $2 \mathrm{~h} /$ day

- Do not consume sugar sweetened beverages e.g. Pepsi

- $\quad$ Eat breakfast daily and can use low or free fat milk and whole grain bread

- $\quad$ Limit meals outside the home like fast food

- $\quad$ Eat two meals per week containing fish

- Have family meals at least 5-6 times/week

- Drink a glass of water before each meal and decreasesalt in food to ovoid fluids retention in the body

- $\quad$ Eat slowly and grind food well

- Do not fill stomach or fill the palate with a largeamount of food.

- $\quad$ Eat three main meals and 2 healthy snacks

Family physician motivated Saad in management plan to help him to reduce his weight such as reduce oilwhen cocking the food in home and replaced saturated fat by unsaturated fat. Family physician also explain for Saad the benefit and importance of exercise both as an intervention for losing weight and for health status as all.He gave Saad the following advices $[49,57]$ :

- Participate in at least $60 \mathrm{~min}$ of moderate to vigorous physical activity per day for 5 days/week and no morethan 2 days without exercise.

- Use proper shoes and choose the proper time for practicing exercise.

- Do not practices exercise after heavy meal? If there is a chest pain stop and seek medical advice.

- $\quad$ Practice muscle strengthening activity at least 3 days/week and bone strengthening activity at least 3 days/week.

- Increase his daily activity through climbing stair instead of using elevators, stop car far from market during shopping, walk to mosque instead of using car, and participate in home tasks e.g. cleaning own car.

Saad showed genuine interest in the action plan. He promised his family physician to adhere to the agreed action plan and contact the family physician for any complaint or issues. An appointment after one month was given.

$\mathbf{5}^{\text {th }}$ visit: This visit was the first visit after the action plan was agreed. So, family physician was interested in this visit specifically to assess Saad's adherence to action plan, if there was any complaint or active issue. 
There was no any active issue or complaint. Saad was happy as he achieves $(2 \mathrm{~kg})$ weight reduction. Family physician interested in that achievement and encourages Saad to continue in same manner (Maintenance). Then, he checked with Saad the logbook for diet and physical activity. The adherence to the action plan was in general excellent with promising results. The family of Saad was supporting for his goal of weight reduction. The action plan was reviewed with Saad to fill the gaps and solve challenging problems.

At the end of the visit, family physician thanked Saad for his achievement and tells him to back again or contact the clinic if faced any issue or problem. The next visit was agreed to be after 2 months.

$6^{\text {th }}$ visit: Family physician welcomed Saad at his clinic who attained on time. He thanked Saad for his punctuality. Brief history and physical examination was undertaken as well as the weight and BMI. The new weight was $95 \mathrm{~kg}$ and BMI $=29.32 \mathrm{~kg} / \mathrm{m}^{2}(4 \mathrm{~kg}$ weight loss since previous visit).

Saad wondered if he can use weight reduction medications as they will accelerate the loss of weight process. Family physician discuss with Saad the pros and cons of such interventions. He demonstrated for him by scientific evidences, in simple language, that drug therapy for obesity should be for patients who did not achieve the optimum weight reduction with behavioral interventions [49]. He decided to continue vigorously in the behavioral interventions as he satisfied with the evidence introduced by his family physician and productive discussion. Family physician thanked Saad and agreed with him to meet again after 2-months.

$7^{\text {th }}$ visit: After the vital signs, weight, height and BMI were taken and measured, Saad met his family physician with new look as he lost a $5 \mathrm{~kg}$ since last appointment. His weight was $90 \mathrm{~kg}$ and $\mathrm{BMI}=27.78 \mathrm{~kg} /$ $\mathrm{m}^{2}$. Saad was very grateful to his family physician as he helped him in changing his thoughts about obesity as well as unhealthy behaviors. He mentioned that many aspects of his life were changed and improved surprisingly. His mood, sleep quality, daily activity, concentration and achievement in work all were changed and improved. Family physician was glad by the changed of Saad status as all. He demonstrated to Saad that he did a great job, as he arrived to this weight. He promised him with more improvement in his quality of life after completion of the action plan. An appointment was given to Saad after 3 months as he will go to annual vacation. Family physician provide Saad with tips about social events participation as it may has detrimental effect on agreed action plan for weight reduction.

\section{Telephone consultation}

After 6 weeks, family physician contact Saad on his mobile telephone and discussed with him recent changed and obstacles regarding his lifestyles in the vacation. Saad reported some difficulties in meaning of maintain the healthy diet during social events. But overall, he lost $3 \mathrm{~kg}$ during the past weeks. Family physician encouraged Saad to make the weight reduction top priority to achieve the target smoothly. He reassured Saad that some regress during implication of weight reduction action plan is normal and fair common and expected. So, all what Saad need to do is maintaining a strong desire to change and do not give up. He provided him with some tips before and after participation in social events such as drinking water, vegetables, and juices before going to events. Family physician stressed on keeping the contact with him easy at any time he need such thing. Saad thanked family physician for his attention and promised his physician to adhere to the action plan as was agreed before.

$\mathbf{8}^{\text {th }}$ visit: Saad came to the clinic on time and brief histories as well as physical examination were undertaken. The weight of Saad at this visit was $83 \mathrm{~kg}$ and $\mathrm{BMI}=25.61 \mathrm{~kg} / \mathrm{m}^{2}$. There was no active complaint or active issue. Family physician thanked Saad for his adherence to the action plan despite faced challenged during the vacation. Hopefully, the wife of Saad as well as two of Saad's brothers started to follow the action plan to reduce their weight. Saad encouraged by his family physician to continue in same manner to achieve the agreed goal. Family physician thanked Saad and gave him an appointment after 2-months.

$\mathbf{9}^{\text {th }}$ visit: Family physician welcomed Saad at the door of clinic. Measuring his weight and height by himself and reviewed the action plan together. His current weight was79kg (4kg lost) and $\mathrm{BMI}=24.38 \mathrm{~kg} / \mathrm{m}^{2}$. New appointment for Saad was given after 2-months.

$10^{\text {th }}$ visit: Saad entered the clinic saying "finally doctor, I have reached the goal". Family physician congratulates and celebrates with Saad for his achievement and patience for this successful and long journey of attitude and behavior change. Saad weight at that moment was $74 \mathrm{~kg}$ ( $5 \mathrm{~kg}$ lost $)$ and $\mathrm{BMI}=22.83 \mathrm{~kg} / \mathrm{m}^{2}$. Family physician encouraged Saad to continue in a lifelong healthful life style to maintain his weight and prevent relapse. Family physician stressed on Saad that his clinic and telephone is available at any time for assistance and helping.

\section{Conclusion}

Obesity is a major health problem. The role of family physician is of most important in prevent, treat and educate patients about that health problem. The cycle and stages of change should be used by family physician to encourage patients to change their wrong thoughts as well as unhealthful behaviors. They are simple and practical and easily applicable in primary care setting. What we need is patience and cooperation with patient and never give-up in trying to change the thoughts and behaviors of patient as they are the unit of healthy community.

\section{References}

1. Khan LK, Bowman BA. Obesity: a major global public health problem. Annu Rev Nutr. 1999; 19: xiii-xvii.

2. Ng M, Fleming $T$, Robinson $M$, et al. Global, regional, and national prevalence of overweight and obesity in children and adults during 1980-2013- a systematic analysis for the Global Burden of Disease Study 2013. The Lancet. 2014; 384: 766-781.

3. Adult obesity at-a-glance. 2014.

4. Forouzanfar $\mathrm{MH}$, Afshin $\mathrm{A}$, Alexander $\mathrm{LT}$, et al. Global, regional, and national comparative risk assessment of 79 behavioural, environmental and occupational, and metabolic risks or clusters of risks, 1990-2015: a systematic analysis for the Global Burden of Disease Study 2015. The Lancet. 2016; 388: 1659-1724.

5. Trends in adult body-mass index in 200 countries from 1975 to 2014: a pooled analysis of 1698 population-based measurement studies with $19 \cdot 2$ million participants. The Lancet. 2016; 387: 1377-1396.

6. McTigue K, Larson JC, Valoski A, et al. Mortality and cardiac and vascular outcomes in extremely obese women. JAMA. 2006; 296: 79-86. 
7. Body-mass index and all-cause mortality: individual-participant-data metaanalysis of 239 prospective studies in four continents. The Lancet. 2016; 388: 776-786.

8. Yan LL, Daviglus ML, Liu K, et al. Midlife body mass index and hospitalization and mortality in older age. JAMA. 2006; 295: 190-198.

9. Adams KF, Schatzkin A, Harris TB, et al. Overweight, Obesity, and Mortality in a Large Prospective Cohort of Persons 50 to 71 Years Old. N Engl J Med. 2006; 355: 763-778.

10. Flegal KM, Graubard BI, Williamson DF, Gail MH. Cause-specific excess deaths associated with underweight, overweight, and obesity. JAMA. 2007; 298: 2028-2037.

11. Prospective Studies C. Body-mass index and cause-specific mortality in 900000 adults: collaborative analyses of 57 prospective studies. The Lancet. 2009; 373: 1083-1096.

12. Kramer CK, Zinman B, Retnakaran R. Are metabolically healthy overweight and obesity benign conditions?: A systematic review and meta-analysis. Ann Intern Med. 2013; 159: 758-769.

13. Flegal KM, Kit BK, Orpana H, Graubard BI. Association of all-cause mortality with overweight and obesity using standard body mass index categories: A systematic review and meta-analysis. JAMA. 2013; 309: 71-82.

14. Cerhan JR, Moore SC, Jacobs EJ, et al. A Pooled Analysis of Waist Circumference and Mortality in 650,000 Adults. Mayo Clin Proc. 2014; 89 ; 335-345.

15. Haslam DW, James WPT. Obesity. The Lancet. 2005; 366: 1197-1209.

16. Visscher TS, Rissanen A, Seidell JC, et al. Obesity and unhealthy life-years in adult finns: An empirical approach. Arch Intern Med. 2004; 164: 1413-1420.

17. Murphy NF, MacIntyre K, Stewart S, Hart CL, Hole D, McMurray JJV. Longterm cardiovascular consequences of obesity: 20-year follow-up of more than 15000 middle-aged men and women (the Renfrew-Paisley study). Eur Heart J. 2006; 27: 96-106.

18. Bogers RP, Bemelmans WE, Hoogenveen RT, et al. Association of overweight with increased risk of coronary heart disease partly independent of blood pressure and cholesterol levels: A meta-analysis of 21 cohort studies including more than 300000 persons. Arch Intern Med. 2007; 167: 1720 1728.

19. Kenchaiah S, Evans JC, Levy D, et al. Obesity and the Risk of Heart Failure. N Engl J Med. 2002; 347: 305-313.

20. Tedrow UB, Conen D, Ridker PM, et al. The Long- and Short-Term Impact of Elevated Body Mass Index on the Risk of New Atrial Fibrillation: The WHS (Women's Health Study). J Am Coll Cardiol. 2010; 55: 2319-2327.

21. Wang $\mathrm{TJ}$, Parise $\mathrm{H}$, Levy $\mathrm{D}$, et al. Obesity and the risk of new-onset atria fibrillation. JAMA. 2004; 292: 2471-2477.

22. Separate and combined associations of body-mass index and abdominal adiposity with cardiovascular disease: collaborative analysis of 58 prospective studies. Lancet. 2011; 377: 1085-1095.

23. Metabolic mediators of the effects of body-mass index, overweight, and obesity on coronary heart disease and stroke: a pooled analysis of 97 prospective cohorts with $1 \cdot 8$ million participants. The Lancet. $2014 ; 383: 970$ 983.

24. Wilson PF, D'Agostino RB, Sullivan L, Parise H, Kannel WB. Overweight and obesity as determinants of cardiovascular risk: The framingham experience. Arch Intern Med. 2002; 162: 1867-1872.

25. Huang Z, Willett WC, Manson JE, et al. Body weight, weight change, and risk for hypertension in women. Ann Intern Med. 1998; 128: 81-88.

26. Cloostermans L, Wendel-Vos W, Doornbos G, et al. Independent and combined effects of physical activity and body mass index on the development of Type 2 Diabetes - a meta-analysis of 9 prospective cohort studies. Int 3 Behav Nutr Phys Act. 2015; 12: 147

27. Juonala M, Magnussen CG, Berenson GS, et al. Childhood Adiposity, Adult Adiposity, and Cardiovascular Risk Factors. N Engl J Med. 2011; 365: 1876
1885.

28. Colditz GA, Willett WC, Rotnitzky A, Manson JE. Weight gain as a risk factor for clinical diabetes mellitus in women. Ann Intern Med. 1995; 122: 481-486.

29. Willett WC, Dietz WH, Colditz GA. Guidelines for Healthy Weight. N Engl J Med. 1999; 341: 427-434.

30. Hubert HB, Feinleib M, McNamara PM, Castelli WP. Obesity as an independent risk factor for cardiovascular disease: a 26-year follow-up of participants in the Framingham Heart Study. Circulation. 1983; 67: 968-977.

31. Katzel LI, Coon PJ, Rogus E, Krauss RM, Goldberg AP. Persistence of Low HDL-C Levels After Weight Reduction in Older Men With Small LDL Particles. Arterioscler Thromb Vasc Biol. 1995; 15: 299-305.

32. Ageno W, Becattini C, Brighton T, Selby R, Kamphuisen PW. Cardiovascular risk factors and venous thromboembolism: a meta-analysis. Circulation. 2008; 117: 93-102.

33. Eichinger S, Hron G, Bialonczyk C, et al. Overweight, obesity, and the risk of recurrent venous thromboembolism. Arch Intern Med. 2008; 168: 1678-1683.

34. Rapp K, Schroeder J, Klenk J, et al. Obesity and incidence of cancer: a large cohort study of over 145,000 adults in Austria. Br J Cancer. 2005; 93: 1062 1067.

35. Pan SY, Johnson KC, Ugnat A-M, Wen SW, Mao Y, Group tCCRER. Association of Obesity and Cancer Risk in Canada. Am J Epidemiol. 2004; 159: 259-268.

36. Renehan AG, Tyson M, Egger M, Heller RF, Zwahlen M. Body-mass index and incidence of cancer: a systematic review and meta-analysis of prospective observational studies. The Lancet. 2008; 371: 569-578.

37. Bhaskaran K, Douglas I, Forbes H, dos-Santos-Silva I, Leon DA, Smeeth L. Body-mass index and risk of 22 specific cancers: a population-based cohort study of 5.24 million UK adults. The Lancet. 2014; 384: 755-765.

38. Loef M, Walach H. Midlife obesity and dementia: Meta-analysis and adjusted forecast of dementia prevalence in the United States and china. Obesity. 2013; 21: E51-E55.

39. Robinson HE, O'Connell CM, Joseph KS, McLeod NL. Maternal Outcomes in Pregnancies Complicated by Obesity. Obstet Gynecol. 2005; 106: $1357-$ 1364.

40. Ovesen P, Rasmussen S, Kesmodel U. Effect of Prepregnancy Materna Overweight and Obesity on Pregnancy Outcome. Obstet Gynecol. 2011; 118: 305-312.

41. Aune D, Saugstad O, Henriksen T, Tonstad S. Maternal body mass index and the risk of fetal death, stillbirth, and infant death: A systematic review and meta-analysis. JAMA. 2014; 311: 1536-1546.

42. Meehan S, Beck CR, Mair-Jenkins J, Leonardi-Bee J, Puleston R. Maternal Obesity and Infant Mortality: A Meta-Analysis. Pediatrics. 2014; 133: 863871.

43. Hart DJ, Spector TD. The relationship of obesity, fat distribution and osteoarthritis in women in the general population: the Chingford Study. J Rheumatol. 1993; 20: 331-335.

44. Spector TD, Hart DJ, Doyle DV Incidence and progression of osteoarthritis in women with unilateral knee disease in the general population: the effect of obesity. Ann Rheum Dis. 1994; 53: 565-568.

45. Jordan JM, Luta G, Renner JB, et al. Self-reported functional status in osteoarthritis of the knee in a rural southern community: The role of sociodemographic factors, obesity, and knee pain. Arthritis Rheum. 1996; 9: 273-278.

46. Hampel H, Abraham NS, El-Serag HB. Meta-analysis: Obesity and the risk for gastroesophageal reflux disease and its complications. Ann Intern Med. 2005; 143: 199-211.

47. Zimmerman GL, Olsen CG, Bosworth MF. A 'stages of change' approach to helping patients changes behavior. Am Fam Physician. 2000; 61: 1409-1416.

48. Rakel RE, Rakel D. Textbook of Family Medicine. $9^{\text {th }}$ Edition ed: Elsevie Health Sciences; 2015 
49. Al-Shehri F, Moqbel M, Al-Khaldi $\mathrm{Y}$, et al. Prevention and management of obesity: Saudi guideline update. Saudi J Obeity. 2016; 4: 25-40.

50. Prochaska JO, DiClemente CC, Norcross JC. In search of how people change: applications to addictive behaviors. Am Psychol. 1992; 47: 1102.

51. Britt E, Hudson SM, Blampied NM. Motivational interviewing in health settings: a review. Patient Educ Couns. 2004; 53: 147-155.

52. Prochaska JO, Velicer WF, Rossi JS, et al. Stages of change and decisional balance for 12 problem behaviors. Health Psychol. 1994; 13: 39-46.

53. Glanz K, Patterson RE, Kristal AR, et al. Stages of Change in Adopting Healthy Diets: Fat, Fiber, and Correlates of Nutrient Intake. Health Educ Behav. 1994; 21: 499-519.

54. Grimley DM, Riley GE, Bellis JM, Prochaska JO. Assessing the Stages of
Change and Decision-Making for Contraceptive Use for the Prevention of Pregnancy, Sexually Transmitted Diseases, and Acquired Immunodeficiency Syndrome. Health Educ Behav. 1993; 20: 455-470.

55. Hellman EA. Use of the Stages of Change in Exercise Adherence Mode Among Older Adults With a Cardiac Diagnosis. J Cardiopulm Rehabil Prev. 1997; 17: 145-155.

56. Campbell MK, DeVellis BM, Strecher VJ, Ammerman AS, DeVellis RF, Sandler RS. Improving dietary behavior: the effectiveness of tailored messages in primary care settings. Am J Public Health. 1994; 84: 783-787.

57. Al-Saleh M, Al-Zahrani M. Obese child: A practical approach. Saudi J Obeity. 2015; 3: 21-25
J Fam Med - Volume 4 Issue 4 - 2017

ISSN : 2380-0658 | www.austinpublishing group.com

Algarni et al. ( All rights are reserved
Citation: Al-Saleh MM and Algarni AM. Assess Obese Patient Readiness to Decrease Weight: A Practical Approach. J Fam Med. 2017; 4(4): 1121. 